\title{
Nitrogen assimilation in Citrus based on CitEST data mining
}

\author{
Ester Wickert ${ }^{1}$, Jackson Marcondes ${ }^{2}$, Manoel Victor Lemos ${ }^{3}$ and Eliana G.M. Lemos ${ }^{2}$ \\ ${ }^{1}$ Departamento de Fitossanidade, Faculdade de Ciências Veterinárias, Universidade Estadual Paulista, \\ Jaboticabal, SP, Brazil. \\ ${ }^{2}$ Departamento de Tecnologia, Faculdade de Ciências Veterinárias, Universidade Estadual Paulista, \\ Jaboticabal, SP, Brazil. \\ ${ }^{3}$ Departamento de Biologia Aplicada a Agropecuária, Faculdade de Ciências Veterinárias, \\ Universidade Estadual Paulista, Jaboticabal, SP, Brazil.
}

\begin{abstract}
Assimilation of nitrate and ammonium are vital procedures for plant development and growth. From these primary paths of inorganic nitrogen assimilation, this metabolism integrates diverse paths for biosynthesis of macromolecules, such as amino acids and nucleotides, and the central intermediate metabolism, like carbon metabolism and photorespiration. This paper reports research performed in the CitEST (Citrus Expressed Sequence Tag) database for the main genes involved in nitrogen metabolism and those previously described in other organisms. The results show that a complete cluster of genes involved in the assimilation of nitrogen and the metabolisms of glutamine, glutamate, aspartate and asparagine can be found in the CitEST data. The main enzymes found were nitrate reductase (NR), nitrite reductase (NiR), glutamine synthetase (GS), glutamate synthetase (GOGAT), glutamate dehydrogenase (GDH), aspartate aminotransferase (AspAT) and asparagine synthetase (AS). The different enzymes involved in this metabolism have been shown to be highly conserved among the Citrus and Poncirus species. This work serves as a guide for future functional analysis of these enzymes in citrus.
\end{abstract}

Key words: nitrogen assimilation, citrus, CitEST datamining.

Received: July 21, 2006; Accepted: April 2, 2007.

\section{Introduction}

Nitrate $\left(\mathrm{NO}_{3}{ }^{-}\right)$and ammonium $\left(\mathrm{NH}_{4}^{+}\right)$are the main resources of inorganic nitrogen $\left(\mathrm{N}_{2}\right)$ absorbed by the roots of higher plants. Assimilation of inorganic nitrogen present within the atmosphere into carbon skeletons is fundamentally important to plant productivity, biomass production and, especially, cultivation income. Nitrogen deficiency in plants is considered to cause a decrease in photosynthetic structural compounds, like chlorophyll and ribulose bisphosphate carboxylase (rubisco), which leads to a reduction in photosynthetic capacity and carboxylation efficiency (Delgado et al., 1994). Nitrogen is used to form glutamine, a precursor of many amino acids, like nucleic acids, alkaloids and polysaccharides, as well as secondary metabolites like polyamines (Bagh et al., 2004).

Nitrate corresponds to the dominant nitrogen source available for plants, since ammonium is quickly nitrated by bacteria in soil. Only when nitrification conditions are un-

Send correspondence to Eliana G.M. Lemos, Departamento de Tecnologia, Faculdade de Ciências Veterinárias, Universidade Estadual Paulista, Via de acesso Paulo Donato Castellane s/n, 14884-900, Jaboticabal, SP, Brazil. E-mail: egerle@fcav.unesp.br. favorable, like in acidified soils or due to the lack of aeration, can $\mathrm{NH}_{4}{ }^{+}$be the main available form.

Nitrate may be processed by both root and leaf cells. It is used by higher plants in various processes, including absorption, vacuole storage, xylem transport, reduction and incorporation into organic forms. Since most plants perform nitrate vacuole storage and tolerate high ion concentrations, it is reasonable to assume that nitrate has an important function as an osmotic agent (Lasa et al., 2002).

The carbon and nitrogen assimilation metabolic systems are interconnected; nitrogen assimilation requires carbohydrates to produce energy and to provide carbon skeletons. While nitrate may accumulate in vacuoles, ammonium ions are toxic and have to be rapidly assimilated into organic compounds (Chaillou et al., 1994). Consequently, ammonium assimilation requires the availability of carbon skeletons and promotes carbon flow in the TCA cycle (Turpin et al., 1988).

Inorganic nitrogen is assimilated and organically incorporated into glutamine, glutamate, asparagine and aspartate, which constitute important nitrogen carriers inside the plant. These primary amino acids are the main com- 
pounds of the total free amino acid pool in many plants, which are utilized for the synthesis of other amides, like ureides, other amino acids and amines.

All inorganic nitrogen is first reduced to $\mathrm{NH}_{4}{ }^{+}$before it is incorporated into organic forms. $\mathrm{NO}_{3}{ }^{-}$reduction to $\mathrm{NH}_{4}{ }^{+}$is mediated by two key enzymes, nitrate reductase (NR) and nitrite reductase (NiR). NR catalyzes the reduction of two electrons for the conversion of nitrate into nitrite, as explained in Table 1 and Figure 1. NiR turns nitrite into ammonium through a reduction of six electrons and the ammonium is then converted to glutamine, which is essential for amino acid synthesis via the glutamine synthetase (GS) and glutamate synthetase (GOGAT) system. This metabolic system is regulated at different levels by many factors, including nitrogen source and light, in order to adjust nitrate assimilation to the plant's needs. Nitrate acts as an elicitor inducing the transcription of nitrate transporters and NR/NiR genes (Hoff et al., 1994; Forde, 2000) and regulating their expression together with light (Bouton et al., 2002).

In Arabidopsis, ammonium originates from nitrate reduction, direct absorption, photorespiration, dinitrogen fixation $\left(\mathrm{N}_{2}\right)$ or deamination of nitrogenous compounds, such as asparagine. Ammonium can be metabolized into glutamate (glutamic acid) through glutamate dehydrogenase (GDH) or into glutamine through GS/GOGAT (Pierleoni et al., 2001).

In the GS/GOGAT pathway, ammonium is assimilated into organic molecules primarily by the combined catalytic action of two enzymes: glutamine synthetase (GS, L-glutamate:ammonia-ligase; EC 6.3.1.2) and glutamate synthase (GOGAT, L-glutamate:ferredoxinoxidoreductase; EC 1.4.7.1) (Lea and Miflin, 2003).

Table 1 - Enzymes and biochemical reactions for plant nitrogen assimilation (Lam et al., 1996).

\begin{tabular}{|c|c|}
\hline Enzyme & Reaction \\
\hline NR & $\begin{array}{l}\mathrm{NO}_{3}^{-}+\mathrm{NAD}(\mathrm{P}) \mathrm{H}+\mathrm{H}^{+}+2 e^{-}=\mathrm{NO}_{2}^{-}+\mathrm{NAD}(\mathrm{P})+ \\
\mathrm{H}_{2} \mathrm{O}\end{array}$ \\
\hline NiR & $\begin{array}{l}\mathrm{NO}_{2}^{-}+\mathrm{Fd}(\mathrm{red})+8 \mathrm{H}^{+}+6 e^{-}=\mathrm{NH}_{4}^{+}+\mathrm{Fd}(\mathrm{ox})^{+} \\
2 \mathrm{H}_{2} \mathrm{O}\end{array}$ \\
\hline GS1/GS2 & glutamate $+\mathrm{NH}_{4}^{+}+\mathrm{ATP}=$ glutamine $+\mathrm{ADP}+\mathrm{Pi}$ \\
\hline Fd-GOGAT & $\begin{array}{l}\text { glutamine }+2 \text {-oxoglutarate }+2 \mathrm{Fd}(\mathrm{red})=2 \text { gluta- } \\
\text { mate }+2 \mathrm{Fd}(\text { ox })\end{array}$ \\
\hline NADH-GOGAT & $\begin{array}{l}\text { glutamine }+2 \text {-oxoglutarate }+2 \mathrm{NADH}=2 \text { gluta- } \\
\text { mate }+\mathrm{NAD}\end{array}$ \\
\hline GDH & $\begin{array}{l}\text { glutamate }+\mathrm{H}_{2} \mathrm{O}+\mathrm{NAD} / \mathrm{NADP}=\mathrm{NH}_{4}^{+}+2 \text {-oxo- } \\
\text { glutarate }+\mathrm{NADH} / \mathrm{NADPH}\end{array}$ \\
\hline AspAT & $\begin{array}{l}\text { glutamate }+ \text { oxaloacetate }=\text { aspartate }+ \\
\text { 2-oxoglutarate }\end{array}$ \\
\hline AS & $\begin{array}{l}\text { glutamine }+ \text { aspartate }+ \text { ATP }=\text { asparagine }+ \text { glu- } \\
\text { tamate }+ \text { AMP }+ \text { PPi }\end{array}$ \\
\hline
\end{tabular}

Abbreviations: GS1, cytoplasmic glutamine synthetase; GS2, chloroplastic glutamine synthetase; Fd-GOGAT, ferredoxin-dependent glutamate synthase; NADH-GOGAT, NADH-dependent glutamate synthase; GDH, glutamate dehydrogenase; AspAT, aspartate aminotransferase; AS, asparagine synthetase; Fd, ferredoxin; Pi, inorganic phosphate; PPi, pyrophosphate.
Most leaf cells of higher plants possess two GS isoforms: one is cytosolic (GS1) and the other is located in the chloroplast stroma (GS2) (Santos et al., 2004). The GS isoenzymes are located in specific organs and cells, which suggests that there is no functional overlap in plant metabolism (Pereira et al., 1992). It has been suggested that GS2 plays a role in the assimilation of ammonium produced by nitrate reduction and/or photorespiration. While in young blossoms, the GS1 cytosolic isoform is located in the phloem accompanying cells (Carvalho et al., 1992; Pereira et al., 1992) and is likely to be involved in nitrogen remobilization and amide synthesis during senescence (Bauer et al., 1997).

In the chloroplast of mesophyll cells of higher plants, a specific GS isoform (GS2) and a ferredoxin-dependent GOGAT (Fd-GOGAT) are responsible for most of the nitrogen assimilation. The GS/GOGAT pathway transfers ammonium to glutamate to form glutamine in an ATPdependent reaction; the fixed nitrogen is then transferred to a carbon skeleton in the form of 2-oxoglutarate, an organic acid, for the biosynthesis of two glutamate molecules (Gálvez et al., 1999).

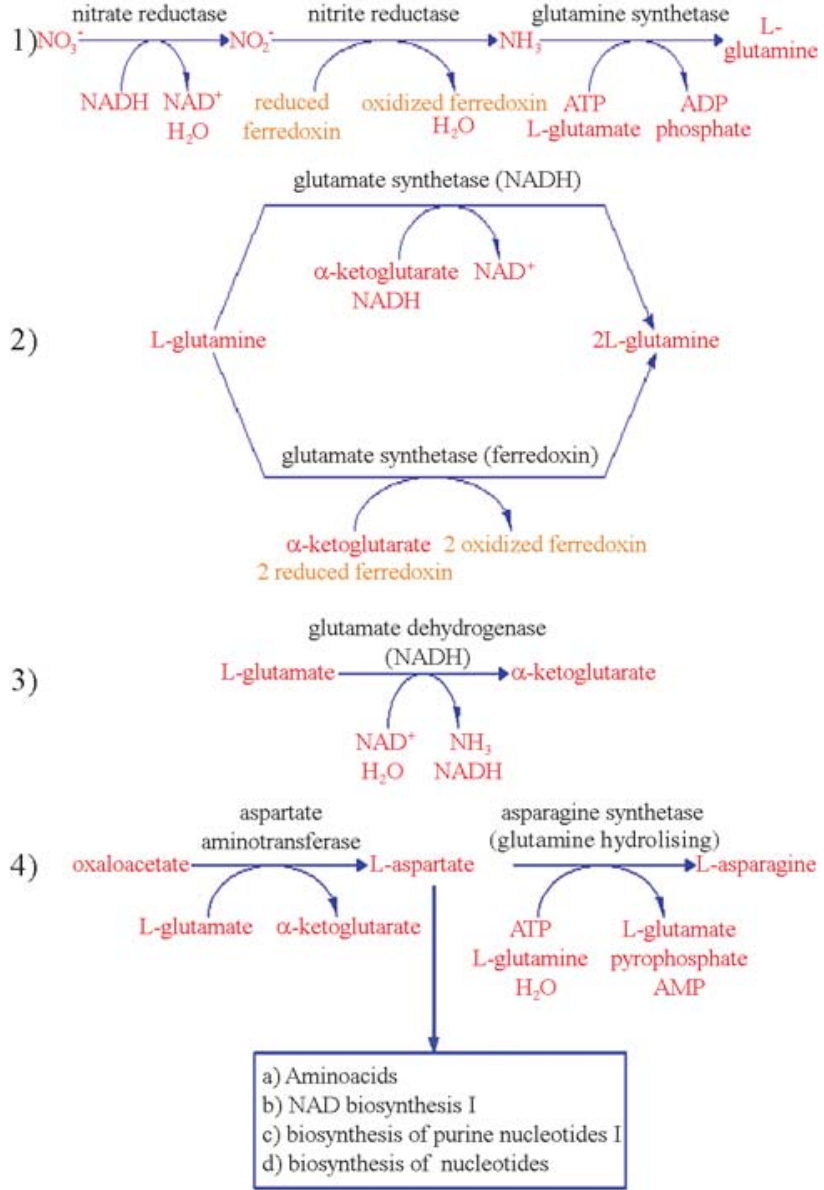

Figure 1 - The role of enzymes and metabolic pathways in nitrogen metabolism (AraCyc): A) Nitrate assimilation pathway and biosynthesis of glutamine; B) Ammonium assimilation cycle and biosynthesis of glutamate; C) Glutamate degradation; D) Biosynthesis of asparagine and biosynthesis and degradation of aspartate. 
Although the GS/GOGAT metabolic pathway is the main route of nitrogen assimilation in higher plants, these plants possess the ability to use alternative routes, such as the reversible amination of 2-oxoglutarate to produce glutamate by GDH (Lasa et al., 2002).

GDH (L-glutamate:NAD+-oxidoreductase; EC 1.4.1.2) catalyzes the amination of 2-oxoglutarate and the deamination of glutamate and its activity depends on specific environmental conditions (Melo-Oliveira et al., 1996). However, an increase in GDH activity was observed in plants under excessive ammonium stress, which indicates that the enzyme may be involved in the process of plant detoxification (Laurière and Daussant, 1983). Lea and Miflin (2003) suggested that GDH is not essential for glutamate formation; however, it has an important function as a catabolic derivative, which ensures that nitrogen metabolism does not affect mitochondrial function in a negative way, aside from allowing synthesis and transport of nitrogen-rich compounds during remobilization.

Asparagine functions in the transport and storage of nitrogen, in addition to being an essential compound of many proteins required for normal plant development (Sieciechowicz et al., 1988). Asparagine is synthesized by the enzyme asparagine synthetase (AS; EC 6.3.5.4), which is encoded by a variable number of AS genes, depending on the species in question. Most of the plants studied contain a single copy of the AS gene, while the leguminous encode two copies and Arabidopsis thaliana and Helianthus annuus have three copies, although the expression of one copy has not been detected (Lam et al., 1996). The activity of the AS gene is regulated by light, carbon concentration and nitrogen availability (Herrera-Rodriguez et al., 2004).

In summary, NR is responsible for nitrate reduction, which enters the roots producing nitrite in the cytosol and is then transported to the chloroplasts, where it is reduced to ammonia by NiR. The ammonia produced is then fixed into amino acids, glutamine and glutamate, through GS/GOGAT, which serve as substrates for transamination reactions and for the synthesis of other amino acids essential to protein production (Camargos, 2002).

The purpose of this work is to verify whether the seven key enzymes of the nitrogen metabolism (GS, GOGAT, GDH, AspAT, AS, NR and NiR) were among the deposited EST sequences in CitEST (CITrus Expressed Sequence Tag). For identified sequences, we searched for genetic variations and checked whether that variation was related to conditions like plant species, presence of diseases and the tissue origin of the respective mRNA.

\section{Material and Methods}

\section{CitEST database search}

Library construction and description of tools used to perform this search are explained in an introductory paper to this issue. For this study, different citrus species, like Cit- rus spp., Poncirus spp. and Fortunella spp., were submitted to different conditions, like pathogens (Xanthomonas sp., Xylella sp., Phytophthora sp., Guignardia, CiLV, CTV) and stress conditions (hydric and aluminium toxicity) in order to verify the plant response. We also collected samples of different developmental stages in order to determine whether and how these conditions affected citrus plant development. Samples were collected from different tissues, such as leaves, bark, flowers, fruits, roots and seeds. For more details, see the first paper of this special issue.

\section{Enzyme selection}

The main enzymes and biochemical reactions involved in nitrogen metabolism of the dominant organic forms are listed in Table 1. An investigation was made into the CitEST database to search for the main genes involved in nitrogen metabolism previously described in other organisms, as identified through the metabolic pathway of nitrogen assimilation (www.genome.jp/kegg/pathway/map) and enzyme descriptions (www.expasy.org/enzyme).

\section{Similarity analysis in CitEST}

The different sequences for each enzyme found in the CitEST database were aligned in order to verify the level of similarity, and whether different conditions (such as type of tissue, development stage, disease presence and others) were capable of altering their sequence. The sequences were aligned using CLUSTALX v.1.81 software (Thompson et al., 1997) and the generated alignment was used to construct dendrograms in the MEGA version 2.1 software (Kumar et al., 2004), through the Distance Method, the grouping algorithm Neighbor-Joining and the nucleotide replacement model Kimura 2-P.

\section{Similarity analysis with $\mathrm{NCBI}$}

Consensus sequences of each aligned enzyme were used to provide a comparison with EST sequences of the same enzyme in other plants in order to verify the degree of similarity between the EST sequences. The alignments and dendrograms were generated as described above. Nucleotide sequences were compared to sequences from GenBank (accessed through NCBI - National Center for Biotechnology Information) using the BLAST software (Altschul et al., 1997). In order to ensure a more accurate similarity analysis, software in PERL (Practical Extraction and Reporting Language) was used.

\section{Results and Discussion}

\section{Searched enzymes}

A complete set of genes involved in nitrogen assimilation and glutamine, glutamate, aspartate and asparagine metabolism were found in the CitEST database. The main enzymes involved in the nitrate and ammonia assimilation pathways were found in Citrus (Table 1). These enzymes 
are crucial to inorganic nitrogen assimilation and the synthesis of the main amino acid carriers of nitrogen in plants, like glutamine, glutamate, asparagine and aspartate.

Plant metabolic pathways involving these enzymes are shown as a schematic in Figure 1, where the complete primary metabolism of nitrogen associated with other metabolic routes can be observed as it occurs in plants.

The sequences deposited in the CitEST database that are homologous to the studied enzymes are shown in Table 2. Both isoforms of the GOGAT enzyme were found: NADH-GOGAT and Fd-GOGAT; however, it was not possible to differentiate the plastidic and cytoplasmic isoforms of glutamine synthetase: GS1 or GS2. Different libraries from different species, tissues, treatments and cultivation conditions were generated. It was observed that libraries from Citrus sinensis, followed by Citrus reticulata and Poncirus trifoliata were predominant. Probably, regardless of the biological condition analyzed, this predominance of sequences from these species resulted from the experimental design that generated these specific libraries. However, sequences from root libraries were very poor when compared with other tissues.

A total of 361 sequences were found related to the seven studied enzymes. C. sinensis (CS) was the citrus species with the highest number of sequences related to the enzymes (200 reads), followed by C. reticulata (96 reads) and P. trifoliata (59 reads). C. limon had the lowest number of sequences, only 3 , deposited in the database. Sequences for all seven enzymes were present in $C$. sinensis, while $C$. limon only had entries for AspAT (Table 2). Citrus leaf was the tissue with the highest number of sequences (224 reads), followed by fruit tissue (121 reads), bark tissue (13 reads) and then root, which was represented by only 3 sequences. Healthy plants and developing plants were represented by 124 sequences each, followed by sick plants with 104 sequences and stressed plants with only 3 . GS was the enzyme with the highest number of sequences on CitEST (166 reads), followed by Fd-GOGAT (89 reads) and AspAT (50 reads). NADH-GOGAT had only 2 sequences deposited on CitEST. Leaf tissues had all seven enzymes and AspAT was the only enzyme present in all tissues. NADH-GOGAT was detected in leaf tissues but not in fruit tissues. Bark tissues had sequences for GS, Fd-GOGAT, GDH and AspAT enzymes. In root tissues, only AspAT was detected. Healthy and sick plants had all seven enzymes, but each condition had a different number of reads. The same occurred for the stages of plant development. Stressed plants showed only the AspAT enzyme. Sick plants had a lower number of reads for NR, GDH and AspAT than healthy plants, suggesting lower expression levels. Sick plants had a higher number of reads for FdGOGAT than healthy plants. This was the only enzyme that showed a higher level of expression in sick plants than in healthy plants.
A complete nitrogen metabolism pathway in citrus was evident. The different enzymes involved in this metabolism appeared to be conserved between the different species of Citrus. The enzymes GS, GOGAT, GDH, AspAT and AS, which are responsible for the biosynthesis of glutamine, glutamate, aspartate and aspargine, were detected in different libraries. In addition, the NR and NiR enzymes were detected in different libraries. They are responsible for nitrate reduction and the absorption of nitrogen to ammonia that is then incorporated into an organic form. Although the main enzymes involved in nitrogen metabolism were found among different libraries, no single species or analyzed conditions had all seven enzymes studied. It is most likely that these enzymes were not expressed in the analyzed conditions or possibly that the libraries were not sufficiently screened.

Root libraries would have been the primary focus of the nitrogen assimilation analysis here, yet they contributed very little to this work due to the fact that they are so scarce. On the other hand, the leaf and fruit libraries were more abundant.

The first stage in the nitrate assimilation pathway is the reduction of nitrate to nitrite. The reaction is catalyzed by the NR (EC 1.9.6.1) enzyme, a complex metalloenzyme that forms homodimers and homotetramers. Many forms of plant NRs use NADH as a reducing agent, although some of them are bispecific and use both NADPH and NADH. NR and nitrate reduction are located in the cytosol of cells which is spread over all plant organs (Campbell, 1999). In many species, its distribution depends on environmental conditions. Transcription is regulated by nitrate availability in roots and leaves. Other transcription regulating factors are nitrogen supply, sucrose, circadian rhythm, light and cytocynin. $\mathrm{CO}_{2}$ and $\mathrm{O}_{2}$ concentrations also contribute to NR activity regulation (Campbell, 1999). In citrus, NR was detected in leaf and fruit tissues and is probably mainly expressed in leaves. It was not detected in bark and root tissues. In addition, this enzyme's expression is reduced in sick plants.

After the nitrate reduction, the following step of the nitrate assimilation pathway is the reduction of nitrite to ammonia. That reaction is catalyzed by NiR (EC 1.7.2.2) in the chloroplasts and root cells as well as in the aerial parts. Six electrons are transferred in this reaction, as opposed to the two electrons required for nitrate reduction. The source of electrons for nitrite reduction is reduced ferredoxin (Fdx-red), which is produced in chloroplasts as well as in plastids of non-photosynthesizing tissues and in roots. NiR is a nuclear-encoded protein with an N-terminal peptide that is believed to generate the mature enzyme (Wray, 1993). The nitrate's reduction capacity in the chloroplast is considerably higher than it is in the cytosol, partly because the enzyme has a high affinity for nitrite. This is relevant due to the fact that nitrite may intoxicate the plant cell, causing chlorosis when accumulated in the plant. In order 
to prevent nitrite toxicity, the cells must contain enough $\mathrm{NiR}$ to reduce all nitrate produced by NR. Nir is regulated transcriptionally, usually in coordination with NR. Because nitrite is toxic, cells must contain enough NiR to reduce all the nitrite produced by NR. Thus, plantas maintain an excess of NiR activity whenever NR is present by inducing $\mathrm{NiR}$ expression in response to light and nitrate. If $\mathrm{NiR}$ concentrations are diminished, either by mutation or antisense expression, plantas accumulate nitrite and display chlorosis. In wild-type plantas, the regulatory mechanisms that control NR activity are thought to assist in preventing nitrite accumulation (Crawford et al., 2001). This enzyme was observed in leaf and fruit tissues and probably has the same expression level in both. It was also observed in both healthy and sick plants, so its expression apparently was not affected by changes in plant health. This was not observed in root or bark tissue.

Following uptake, inorganic nitrogen is first reduced to ammonia before it is incorporated into the amino acids glutamine and glutamate. Ammonium assimilation usually occurs in the roots, whereas nitrate assimilation can occur in both roots and leaves, depending on species and environmental conditions. Transport to the leaves occurs via the xylem, whereas redistribution from the leaves to other nitrogen-requiring organs occurs predominantly in the form of amino acids via the phloem. This redistribution is essential for supplying tissues that do not participate in nitrogen assimilation (Williams and Miller, 2001). A high proportion of amino acids arriving in the mature leaves is cycled from the xylem into the phloem for redistribution to nitrogen sinks. When assimilation occurs predominantly in the shoot, cycling of amino acids is essential to cover the demands of the roots. According to the same authors, excess amino acids in the root can move from the phloem to the xylem for recycling. Nitrogen can also be transported across the plasma membrane of certain cells in other forms, such as small peptides and purine and pyrimidine bases and their derivatives (Williams and Miller, 2001).

The main enzymes involved in ammonium assimilation are GS, GOGAT and GDH. Each of these enzymes occurs in multiple isoenzymatic forms encoded by distinct genes. The individual isoenzymes of GS, GOGAT and GDH have been proposed to play roles in three major ammonia assimilation processes: primary nitrogen assimilation, re-assimilation of photorespiratory ammonia and re-assimilation of recycled nitrogen (Lam et al., 1996).

Biochemical studies have revealed the existence of multiple isoforms for each of these enzymes. Molecular studies have also demonstrated that each enzyme is encoded by a gene family, wherein individual members encode distinct isoenzymes that are differentially regulated by environmental stimuli, metabolic control, developmental control and tissue/cell-type specificity. More recently, molecular studies have also shown that the genes involved in nitrogen assimilation and metabolism are not constitu- tively expressed "housekeeping genes," but are carefully regulated by factors such as light, metabolites and cell type (Lam et al., 1996).

Two classes of GS (EC 6.3.1.2) isoenzymes that are located in the cytosol (GS1, EC 6.3.1.2) or chloroplast (GS2, EC 6.3.1.2) have been identified (Lam et al., 1996). The distinct physiological roles of GS1 and GS2 have been implicated by their organ-specific distributions. In citrus, GS was observed in leaf, bark and fruit tissues, all of which are photosynthetic tissues. But the GS sequences identified on the CitEST database were mainly found in leaves, which means that these sequences probably belong to the GS2 form. For instance, because GS2 is the predominant isoenzyme in leaves, it has been proposed to function in primary assimilation of ammonia reduced from nitrate in chloroplasts and/or in the re-assimilation of photorespiratory ammonia. The GS2 form is primarily expressed in the mesophyll cells of leaves, where photorespiratory ammonia is released. The analysis of barley mutants deficient in GS2 showed that the main role of this enzyme is in the re-assimilation of ammonia from photorespiration and that GS2 gene expression is tightly regulated by light (ZozayaHinchliffe et al., 2005). GS2 mRNA accumulation has been reported to be higher in leaves of plants cultivated under photorespiratory conditions, which is consistent with the proposed function of the re-assimilation of photorespiratory ammonia (Miflin, 1974). Studies in barley (Hordeum vulgare) also revealed that chloroplastic GS2 is expressed predominantly in leaf mesophyll cells, where photorespiration occurs, whereas cytosolic GS1 is expressed exclusively in phloem (Edwards et al., 1990). However, in citrus, no GS sequence was found in root libraries, probably because few root libraries were available. So, it is probable that the GS1 form was not present among the obtained sequences. Because cytosolic GS1 is predominant in roots, it has been proposed to function in root nitrogen assimilation, although root GS2 has also been implicated in this process. The finding that cytosolic GS1 is the predominant GS isoenzyme expressed during senescence in different plant species suggests that this GS form plays a role in the mobilization of nitrogen for translocation and storage (Lam et al., 1996). It was also verified that plant condition, such as health, sickness, or development stage did not affect the expression level of GS.

In higher plants, there are two distinct forms of GOGAT that use NADH (NADH-GOGAT; E.C.1.4.1.14) or ferredoxin (Fd-GOGAT; E.C.1.4.7.1) as an electron carrier (Lam et al., 1996). NADH-GOGAT is located primarily in plastids of non-photosynthetic tissues such as roots (Suzuki and Gadal, 1984). In root nodules of legumes, NADH-GOGAT is involved in the assimilation of nitrogen fixed by Rhizobium (Anderson et al., 1989). It has been hypothesized that NADH-GOGAT catalyzes the rate-limiting step of ammonia assimilation in these root nodules (Gregerson et al., 1993). In non-leguminous plants, NADH- 
GOGAT may function in the primary assimilation or reassimilation of ammonia released during amino acid catabolism (Miflin and Lea, 1977). This enzyme was poorly expressed in citrus and apparently its expression did not differ in healthy and sick plants. It was only observed in leaves, despite the fact that its main role is in roots.

Contrary to NADH-GOGAT, Fd-GOGAT is located primarily in the leaf chloroplast, where light leads to an increase in Fd-GOGAT protein and activity (Lea et al., 1990). These findings suggested that the physiological role(s) of Fd-GOGAT is related to light-inducible processes in leaves, such as photosynthesis and photorespiration. Fd-GOGAT may also play a smaller role in nonphotosynthetic tissues, because some Fd-GOGAT activity is associated with roots (Suzuki et al., 1982). In citrus, this enzyme was highly expressed in leaves and fruit tissues and its expression was affected by plant condition. Developmental stage was important for this enzyme's expression, because young tissues showed a high number of reads, probably because these tissues have higher levels of photosynthesis and photorespiration activity, which agrees with the findings that this isoenzyme is uniquely found in photosynthetic organisms. The libraries of CitEST also showed that the activity of this enzyme was higher in sick plants. This is most likely due to the higher quantities of organic compounds that act directly as supplies for the plant and indirectly for the pathogen. In another way, the same organic compounds can be also used by the plants to fight the pathogen.

Two major forms of GDH have been reported: an NADH-dependent form (NADH-GDH; E.C.1.4.1.2) found in the mitochondria and an NADPH-dependent form (NADPH-GDH; E.C.1.4.1.4) located in the chloroplast (Day et al., 1988). The GDH enzyme is abundant in several plant organs (Cammaerts and Jacobs, 1985). These studies suggest that GDH may play a specific or unique role in assimilating ammonia or catabolizing glutamate during these processes. In the citrus database, this enzyme was found in leaves, fruits and bark, but it was not possible to differentiate between the two enzyme forms. Sick plants have decreased expression and stressed plants did not express it, which agrees with the findings that the GDH isoenzymatic profile can be influenced by dark stress, natural senescence or fruit ripening (Srivastava and Singh-Rana, 1987).

Following the assimilation of ammonia into glutamine and glutamate, these two amino acids act as important nitrogen donors in many cellular reactions, including the biosynthesis of aspartate and asparagine. Aspartate contributes to the malate-aspartate shuttle that allows the transfer of reducing equivalents from the mitochondria and chloroplast into the cytoplasm. Asparagine is thought to be an important compound for transport and storage of nitrogen resources because of its relative stability and high nitrogen-to-carbon ratio. Asparagine is a major nitrogen-transport compound in both legumes and non-leguminous plants.
Biochemical studies with Pisum sativum showed that AspAT (E.C.2.6.1.1) can exist as distinct isoenzymes. In citrus, this was the only enzyme found in the four analyzed tissues, leaf, fruit, bark and root, with high activity levels in healthy plants at different developmental stages. The activities of various AspAT isoenzymes have been found in different tissues and different subcellular locations, such as the cytosol, mitochondria, chloroplasts, glyoxysomes or peroxisomes (Lam et al., 1996). The subcellular compartmentalization of the AspAT isoenzymes suggest that the different forms of AspAT might serve distinct roles in plant metabolism. It is also important to note that individual AspAT isoenzymes respond differently to environmental conditions and metabolic status, such as light treatment or nitrogen starvation, which suggests that they serve distinct roles (Lam et al., 1996). It was observed in citrus that sick and stressed plants had highly reduced expression of AspAT. In the C3 plant Arabidopsis, the entire gene family of AspAT isoenzymes has been characterized (Schultz and Coruzzi, 1995) and five different AspAT cDNA clones [ASP1-4 and ASP5 (formally AAT1)] were obtained, including those encoding the mitochondrial, plastidic, peroxisomal and cytosolic forms. Even though two of the five $A S P$ genes encode cytosolic forms of AspAT ( $A S P 2$ and $A S P 4$ ), only $A S P 2$ is expressed at high levels, especially in roots (Schultz and Coruzzi, 1995), and this is probably the AspAT form found in citrus root. The $A S P 1$ and $A S P 3$ genes, which encode a mitochondrial and a peroxisomal form of AspAT, respectively, are each expressed at relatively high levels in all organs examined (Schultz and Coruzzi, 1995) and are probably the forms present in the other citrus tissues.

Despite the fact that asparagine was the first amino acid discovered and isolated in asparagus, the mechanism of asparagine biosynthesis in plants was elucidated only recently. The glutamine-dependent AS enzyme (E.C.6.3.5.4) is now generally accepted as the major route for asparagine biosynthesis in plants (Richards and Schuster, 1992). However, ammonia is also a possible AS substrate, particularly in the case of maize roots (Oaks and Ross, 1984). In some cases, asparagine is believed to act as an ammonia detoxification product produced when plants encounter high concentrations of ammonia. In citrus, this enzyme was found in leaves and fruits, with high expression levels in the latter.

The hypothesis that asparagine serves to transport nitrogen in plants is supported by high levels of AS activity detected in nitrogen-fixing root nodules and in cotyledons of germinating seedlings (Lam et al., 1996). This is in agreement with our findings that developmental stages with young tissues have high expression levels of AS. The first two cDNA clones encoding plant AS ( $A S 1$ and $A S 2$ ) were obtained from a pea library and both $A S 1$ and $A S 2$ genes are expressed in leaves as well as in roots. Subsequently, studies of AS cDNA clones isolated from Arabidopsis and asparagus have shown that AS genes in 
these plants are expressed primarily in the leaves or the harvested spears, respectively. Moreover, studies of these AS cDNA clones, together with previous biochemical data, have suggested that asparagine metabolism is regulated by the carbon/nitrogen status of a plant (Lam et al., 1996). The levels of asparagine and AS activity are also controlled by environmental and metabolic signals, such as the presence of pathogens. This can explain the reduced AS activity in sick plants. Both the asparagine content in phloem exudates and AS activity were induced when light-grown plants were dark-adapted (Urquhart and Joy, 1982). The first striking observation of AS gene expression in pea and Arabidopsis was the high level of AS mRNA in dark-grown or dark-adapted plants (Tsai and Coruzzi, 1990). In CitEST, AS was found in leaves and developing fruits.

In contrast to the plants that have two AS genes, sunflower (Helianthus annuus) has three AS (EC 6.3.5.4)-coding genes, HAS1, HAS1.1 and HAS2, that are regulated by light, carbon and nitrogen availability (Herrera-Rodríguez et al., 2004). Thus, in sunflower, asparagine that is needed to sustain growth under normal conditions of light and sufficient carbon can be supplied by $H A S 2$, which is active in those conditions and gives rise to basal levels of asparagine. Limiting carbon or nitrogen excess activates the specialized genes $H A S 1$ and $H A S 1.1$ to alleviate those situations by transforming glutamine to asparagine, a very stable nitrogen carrier with a more favorable nitrogen-to-carbon ratio. Moreover, all three AS genes are induced by ammonium excess in the roots, which might help to assimilate this potentially toxic compound into harmless asparagine. The last two situations result in remarkable increases in endogenous asparagine. Finally, nitrogen starvation activates HAS2 for asparagine synthesis, which might improve nitrogen distribution in the plant (Herrera-Rodríguez et al., 2004).

\section{Similarity analysis in CitEST and with NCBI}

Similarity analysis of AspAT nucleotide sequences in the CitEST database revealed significant differences between the analyzed citrus species (Figure 2). However, it was found that there was similarity between the enzymes of different tissues between healthy and sick tissues and especially between different stages of development and maturation. The same was observed for the other analyzed enzymes: NR, NiR, GS, Fd-GOGAT, NADH-GOGAT, GDH and AS (data not shown).

Because some dissimilarities were observed between the aligned sequences from CitEST, a comparative analysis of the consensus sequence of the selected enzymes in citrus with other plants in the NCBI database was performed. It was verified that the studied enzymes were aligned with dicotyledonous plants, as occurred for GS, which showed greatest similarity to Gossypium and Glycine (Figure 3). This also occurred with the other studied enzymes that showed more similarity with cotton

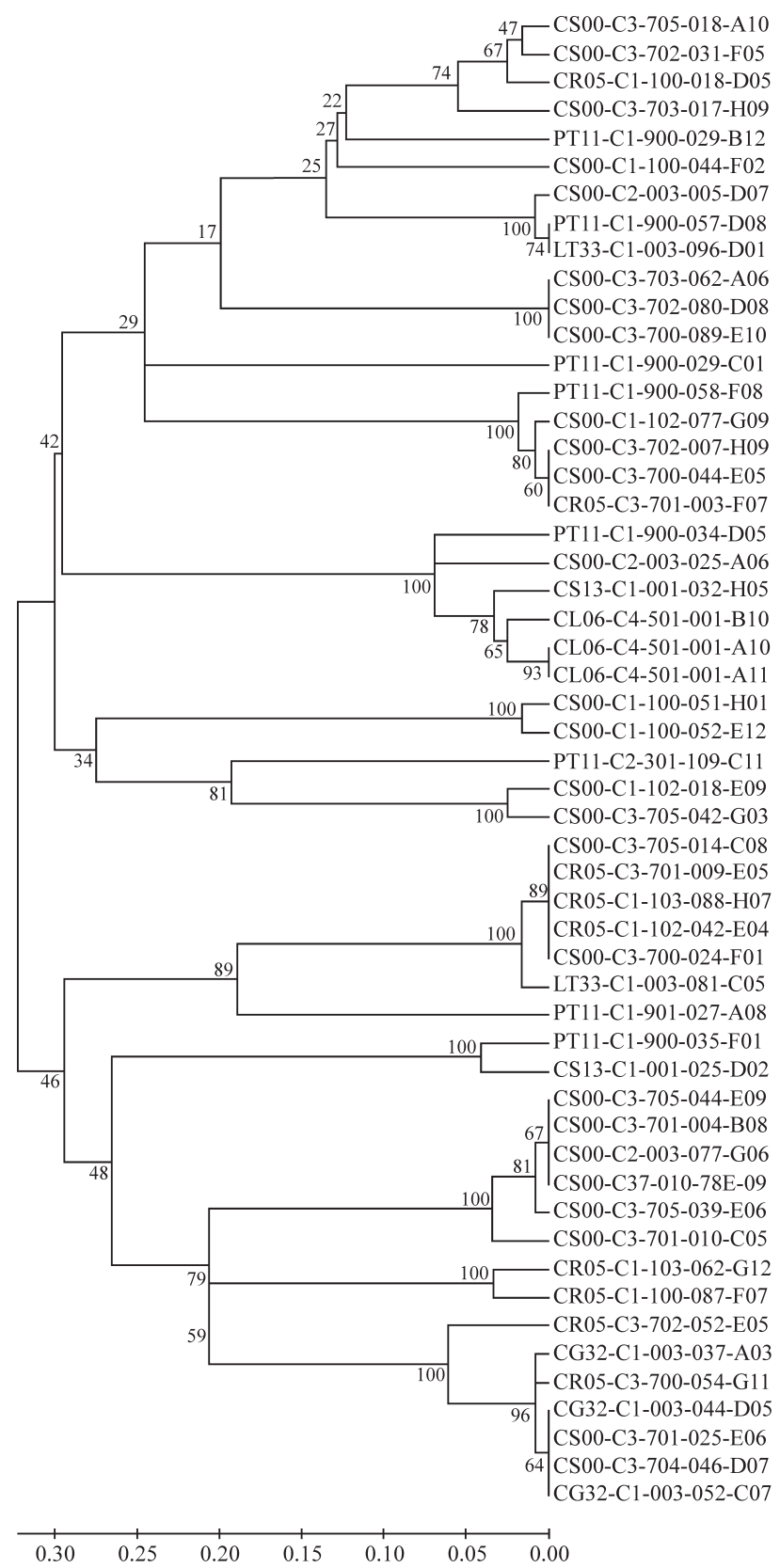

Figure 2 - Dendrogram of ASPaT originating from different species of citric plants, tissues, developmental stages, healthy or infected by pathogens. The first letters and numbers refer to species and variety: CS, Citrus sinensis; CR, Citrus reticulata; PT, Poncirus trifoliata; LT, Citrus latifolia; $\mathrm{CL}$, Citrus limonia; CG, Citrus aurantifolia. For more details on the varieties, see CitEST (http://citest.centrodecitricultura.br/ in CitEST/Nomenclature). The following number and letter refer to tissue type: $\mathrm{C}, \mathrm{cDNA} ; 1$, leaf; 2 , bark; 3 , fruit; 4 , root. The next three numbers refer to plant condition: Stages of development, 700, 701, 702, 703, 704, 705; Stressed plants, 501; Healthy plants, 001, 002, 003, 100; Sick plants, the remaining numbers. For more details, see CitEST as described above. Sequences were not grouped according to a particular condition. It was not possible to observe grouping preference by species, tissue, developmental stage or sick/healthy condition.

(Gossypium hirsutum), peach (Prunus persica) and apple (Malus domestica) than monocotyledons like rice (Oryza sativa), corn (Zea mays) and wheat (Triticum aestivum) 


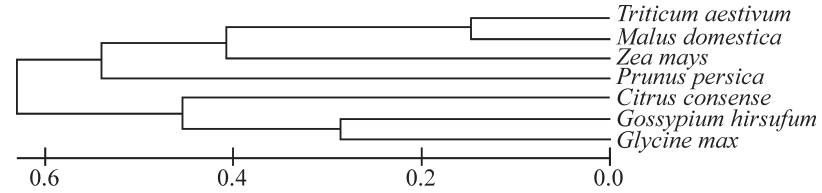

Figure 3 - Homology of the consensus sequence of citrus GS with sequences of GS from other plants obtained from the NCBI database. The greatest similarity is among citrus, Gossypium and Glycine. Accession numbers of used sequences are Triticum aestivum DQ:124214, Malus domestica DY:256358, Zea mays X:65931, Prunus persica DY:654284, Gossypium hirsutum DT:050486 and Glycine max S:46515.

(data not shown), supporting the idea that the nitrogen assimilation mechanism is conserved among plant species.

No significant differences were detected among the sequences of the different enzymes studied here. The alignments were not able to differentiate enzymes in the studied conditions. Enzymes from healthy plants were grouped with enzymes from diseased plants. In addition, enzymes from different species of citrus, from different stages of development and from different tissues were also grouped. Despite the fact that expression levels were altered in some cases, citrus plants contained the main enzymes involved in nitrogen metabolism. We believe that is because the mechanism of nitrogen assimilation is highly conserved among plants and that the differences found in DNA sequences were not related to differences in expression level. Most likely, the enzyme sequences have many differences that were related to natural diversity, because the Citrus genus is known to have great genetic diversity. The different expression levels pertaining to health, disease, tissue type or developmental stage are due to the influences that these conditions have over the transcription of these genes. Studies into the quantitative expression of each enzyme using quantitative real time PCR can be a useful tool for developing a better understanding of whether some particular condition can affect the metabolism of nitrogen assimilation.

Despite the great effort expended in sequencing the ESTs, with approximately $8 \times 10^{5}$ sequences so far, no significant difference was found in nitrogen metabolism among the studied sequences. However, the nitrogen assimilation pathway in citrus plants could be further depicted if the number of root libraries is improved. This notion is consistent with the idea that there is a need to maintain efforts in sequencing in order to achieve a more complete understanding.

\section{Acknowledgements}

We are grateful to $\mathrm{CNPq}$ for support through the Millenium Project.

\section{References}

Anderson MP, Vance CP, Heichel GH and Miller SS (1989) Purification and characterization of NADH-glutamate synthase from alfalfa root nodules. Plant Physiol 90:351-58.

Altschul SF, Madden TL, Schaffer AA, Zhang J, Zhang Z, Miller W and Lipman DJ (1997) Gapped BLAST and PSI-BLAST: A new generation of protein database search programs. $\mathrm{Nu}-$ cleic Acids Res. 25:3389-3402.

Bagh K, Hiraoki T, Thorpe TA and Vogel HJ (2004) Nitrogen-15 NMR studies of nitrogen metabolism in Picea glauca buds. Plant Physiol Biochem 42:803-809.

Bauer D, Biehler K, Fock H, Carrayol E, Hirel B, Migg A and Becker T (1997) A role for cytosolic glutamine synthetase in the remobilisation of leaf nitrogen during water stress in tomato. Physiol Plant 99:241-248.

Bouton S, Leydecker MT, Christian-Meyer C and Truong HN (2002) Role of gibberellins and of the RGA and GAI genes in controlling nitrate assimilation in Arabidopsis thaliana. Plant Physiol Biochem 40:939-947.

Camargos LS (2002) Análise das alterações no metabolismo de nitrogênio em Canavalia ensiformes (L.) em resposta a variações na concentração de nitrato fornecida. Masters Thesis, Escola Superior de Agricultura Luiz de Queiróz, Piracicaba.

Cammaerts D and Jacobs M (1985) A study of the role of glutamate dehydrogenase in the nitrogen metabolism of Arabidopsis thaliana. Planta 163:517-526.

Campbell WH (1999) Nitrate reductase structure, function and regulation: Bridging the gap between biochemistry and physiology. Annu Rev Plant Physiol Plant Mol Biol 50:277-303.

Carvalho H, Pereira S, Sunkel C and Salema R (1992) Detection of a cytosolic glutamine synthetase in leaves of Nicotiana tabacum by immunocytochemical methods. Plant Physiol 100:1591-1594.

Chaillou S, Rideout JW, Raper CD and Morot-Gaudry JF (1994) Responses of soybean to ammonium and nitrate supplied in combination to the whole root system or separately in a split-root system. Physiol Plant 90:259-268.

Crawford NM, Kahn ML, Leustek T and Long SR (2001) Nitrogen and sulfur. In: Buchanan BB, Gruissen W and Jones RL (eds) Biochemistry \& Molecular Biology of Plants. 3rd edition. American Society of Plant Physiologists, Maryland, pp 786-849.

Day DA, Salom CL, Azcon-Bieto J, Dry IB and Wiskich JT (1988) Glutamate oxidation by soybean cotyledon and leaf mitochondria. Plant Cell Physiol 29:1193-1200.

Delgado E, Mitchell RAC, Parry MA, Driscoll SP, Mitchell VJ and Lawdor DV (1994) Interacting effects of CO2 concentration, temperature and nitrogen supply on the photosynthesis and composition of winter wheat leaves. Plant Cell Environ 17:1205-1213.

Edwards JW, Walker EL and Coruzzi GM (1990) Cell-specific expression in transgenic plants reveals nonoverlapping roles for chloroplast and cytosolic glutamine synthetase. Proc Natl Acad Sci USA 87:3459-63.

Forde BG (2000) Nitrate transporters in plants: Structure, function and regulation. Biochim Biophys Acta 1465:219-235.

Gálvez S, Lancien M and Hodges M (1999) Are isocitrate dehydrogenases and 2- oxoglutarate involved in the regulation of glutamate synthesis? Trends Plant Sci 12:484-489. 
Gregerson RG, Miller SS, Twary SN, Gantt JS and Vance CP. (1993) Molecular characterization of NADH-dependent glutamate synthase from alfalfa nodules. Plant Cell 5:215226.

Herrera-Rodríguez MB, Maldonado JM and Pérez-Vicente R (2004) Light and metabolic regulation of HAS1, HAS1.1 and HAS2, three asparagine synthetase genes in Helianthus annuus. Plant Physiol Biochem 42:511-518.

Hoff T, Truong HN and Caboche M (1994) The use of mutants and transgenic plants to study nitrate assimilation. Plant Cell Environ 17:489-506.

Kumar S, Tamura K, and Nei M (2004) MEGA3: Integrated Software for Molecular Evolutionary Genetics Analysis and Sequence Alignment. Briefings in Bioinformatics 5:150-163.

Lam H-M, Coschigano KT, Oliveira IC, Melo-Oliveira R and Coruzzi GM (1996) The molecular-genetics of nitrogen assimilation into amino acids in higher plants. Annu Rev Plant Physiol Plant Mol Biol 47:569-93.

Lasa B, Frechilla S, Aparicio-Tejo PM and Carmen-Lamsfus C (2002) Role of glutamate dehydrogenase and phosphoenolpyruvate carboxylase activity in ammonium nutrition tolerance in roots. Plant Physiol Biochem 40:969-976.

Laurière C and Daussant J (1983) Identification of the ammonium-dependent isoenzyme of glutamate dehydrogenase as the form induced by senescence or darkness stress in the first leaf of wheat. Physiol Plant 58:89-92.

Lea PJ and Miflin BJ (2003) Glutamate synthase and the synthesis of glutamate in plantas. Plant Physiol Biochem 41:555-564.

Lea PJ, Robinson SA and Stewart GR (1990) The enzymology and metabolism of glutamine, glutamate, and asparagine. In: Miflin BJ and Lea PJ (eds) The Biochemistry of Plants. Intermediary Nitrogen Metabolism. Academic Press, New York, pp 121-159.

Melo-Oliveira R, Oliveira IC and Coruzzi GM (1996) Arabidopsis mutant analysis and gene regulation define a nonredundant role for glutamate dehydrogenase in nitrogen assimilation. Proc Natl Acad Sci USA 96:4718-4723.

Miflin BJ (1974) The location of nitrite reductase and other enzymes related to aminoacid biosynthesis in the plastids of root and leaves. Plant Physiol 54:550-555.

Miflin BJ and Lea PJ (1977) Amino acid metabolism. Annu Rev Plant Physiol 28:299-329.

Oaks A and Ross DW (1984) Asparagine synthetase in Zea mays. Can J Bot 62:68-73.

Pereira S, Carvalho H, Sunkel C and Salema R (1992) Immunocytolocalization of glutamine synthetase in mesophyll and phloem of leaves of Solanum tuberosum L. Protoplasma 167:66-73.

Pierleoni R, Vallorani L, Sacconi C, Sisti D, Giomaro G and Stocchi V (2001) Evaluation of the enzymes involved in primary nitrogen metabolism in Tilia platyphyllos - Tuber borchii ectomycorrhizae. Plant Physiol Biochem 39:11111114.

Richards NGJ and Schuster SM (1992) An alternative mechanism for the nitrogen transfer reaction in asparagine synthetase. FEBS Lett 313:98-102.
Santos C, Pereira A, Pereira S and Teixeira J (2004) Regulation of glutamine synthetase expression in sunflower cells exposed to salt and osmotic stress. Sci Hortic 103:101-111.

Schultz CJ and Coruzzi GM (1995) The aspartate aminotransferase gene family of Arabidopsis encodes isoenzymes localized to three distinct subcellular compartments. Plant J 7:61-75.

Sieciechowicz KA, Joy KW and Ireland RJ (1988) The metabolism of asparagine in plants. Phytochemistry 27:663-671.

Srivastava HS and Singh-Rana P (1987) Role and regulation of L-glutamate dehydrogenase activity in higher plants. Phytochemistry 26:597-610.

Suzuki A and Gadal P (1984) Glutamate synthase: Physicochemical and functional properties of different forms in higher plants and other organisms. Physiol Veg 22:471-486.

Suzuki A, Vidal J and Gadal P (1982) Glutamate synthase isoforms in rice: Immunological studies of enzymes in green leaf, etiolated leaf, and root tissues. Plant Physiol 70:827832.

Thompson JD, Gibson TJ, Plewniak F, Jeanmougin F and Higgins DG (1997) The ClustalX windows interface: Flexible strategies for multiple sequence alignment aided by quality analysis tools. Nucleic Acids Res 24:4876-4882.

Tsai F-Y and Coruzzi GM (1990) Dark-induced and organspecific expression of two asparagine synthetase genes in Pisum sativum. EMBO J 9:323-332.

Turpin DH, Elrifi IR, Birch DG, Weger HG and Holmes JJ (1988) Interactions between photosynthesis, respiration, and nitrogen assimilation in microalgae. Can J Bot 66:2083-2097.

Urquhart AA and Joy KW (1982) Transport, metabolism, and redistribution of Xylem-borne amino acids in developing pea shoots. Plant Physiol 69:1226-1232.

Williams LE and Miller AJ (2001) Transporters responsible for the uptake and partitioning of nitrogenous solutes. Annu Rev Plant Physiol Plant Mol Biol 52:659-688.

Wray JL (1993) Molecular biology, genetics and regulation of nitrite reduction in higher plants. Physiol Plant 89:607-612.

Zozaya-Hinchliffe M, Potenza C, Ortega JL and SenguptaGopalan C (2005) Nitrogen and metabolic regulation of the expression of plastidic glutamine synthetase in alfalfa (Medicago sativa). Plant Sci 168:1041-1052.

\section{Internet Resources}

Biochemical pathway database for Arabidopsis (AraCyc) http://www.arabidopsis.org/tools/aracyc (April, 2005).

Citrus Expressed Sequence Tags (CitEST) http://citest. centrodecitricultura.br/ (CitEST/Nomenclature).

NCBI - National Center for Biotechnology Information, http:// www.ncbi.nlm.nih.gov (November 11, 2006).

KEGG: Kyoto Encyclopedia of Genes and Genomes/N metabolism, http://www.genome.jp/kegg/pathway/map. (November 10, 2006).

ExPASy (Expert Protein Analysis System) to enzyme description and identification. http://www.expasy.org/enzyme/. (November 10, 2006).

Associate Editor: Raquel Luciana Boscariol-Camargo 